\title{
Remote Sensing and Geospatial Technologies for Sustainable Development: A Review of Applications
}

\author{
Tri Dev Acharya and Dong Ha Lee*
}

\author{
Department of Civil Engineering, Kangwon National University, \\ 1 Kangwondaehak-gil, Chuncheon, Gangwon 24341, Republic of Korea
}

(Received November 14, 2019; accepted November 26, 2019)

Keywords: remote sensing, geospatial technology, sustainable development, applications, opportunities, challenges

Sustainability requires equilibrium in the use of resources. The United Nations launched 17 Sustainable Development Goals (SDGs) to overcome the world's challenges, including poverty, inequality, and the effects of climate change. Remote sensing (RS) and geospatial technologies have a high potential in monitoring these SDG indicators. In this paper, we briefly introduce these geospatial technologies and their applications to monitoring SDGs along with opportunities and challenges in the current context. RS shows much advancement with new satellites with improved capabilities and whose limitations have been overcome by unmanned aerial vehicles (UAVs). The latest advances have been found in mapping and monitoring various resources, and understanding their relationship with sustainability. New opportunities to adopt emerging technologies with multisource data have been highlighted along with challenges in handling data and manpower. In addition to these, developing countries face challenges in awareness, training, and lack of budget to adopt these technologies, which hinder sustainability in areas that need them the most. In this paper, we provide a brief update to disseminate the latest advances in RS and geospatial technologies for monitoring SDGs and thus raising awareness about their potential applications.

\section{Background}

Sustainability refers to qualitative and quantitative continuity in the use of resources. It implies a state of equilibrium between human activities as influenced by social behavior, acquired knowledge, and applied technology on the one hand and food production on the other. ${ }^{(1)}$ There are several perspectives of sustainability, such as economic, ecological, and social, and an optimum mix of ecological and socioeconomic perspectives. Sustainability attempts not only to address global issues, such as resource degradation, deforestation, and ozone layer depletion, but also local issues, such as the maintenance of socioeconomic systems.

In 2014, a plan entitled "Transforming Our World: The 2030 Agenda for Sustainable Development (Agenda 2030)" was proposed by the United Nations (UN) at the UN Sustainable

*Corresponding author: e-mail: geodesy@kangwon.ac.kr

https://doi.org/10.18494/SAM.2019.2706 
Development Summit to fix global problems. The proposal outlines 17 Sustainable Development Goals (SDGs or Global Goals) to overcome the world's challenges, including poverty, inequality, and the effects of climate change. Figure 1 shows all these SDGs. Globally, most organizations recognized the feasibility of the plan and officially adopted it in September 2015.

In the SDG framework, data produced by geospatial technologies have tremendous potential to effectively and efficiently monitor various indicators of the SDG progress. Geospatial technologies use many types of sensor to produce data and monitor sustainable development measures. Among which, remote sensing (RS) is a fast and cost-effective technique compared with ground-based techniques. Remote electromagnetic sensors measure the location and spectral properties of land cover, which can be analyzed for information extraction. The combination of RS data, in situ monitoring, and reliable geospatial information can provide a measure for natural resources as well as comprehensive hazard and risk assessments. This information is very helpful for sustainable development policymaking, programming, and project operations.

Taking these advances into account, in this paper, we briefly introduce and discuss the applications, opportunities, and challenges related to RS and geospatial technologies for monitoring and information extraction of Earth resources that aid in sustainable development. Furthermore, we focus on emerging challenges and future directions, which can be beneficial to audiences that include researchers, practitioners, and professionals who make decisions on agriculture, environment, forestry, mining, resource management, and urban development targeting SDGs.

\section{Brief Introduction}

Geospatial technology as a whole is any technology that incorporates spatial information in it, i.e., provides location information. In general, the technology is a combination of three

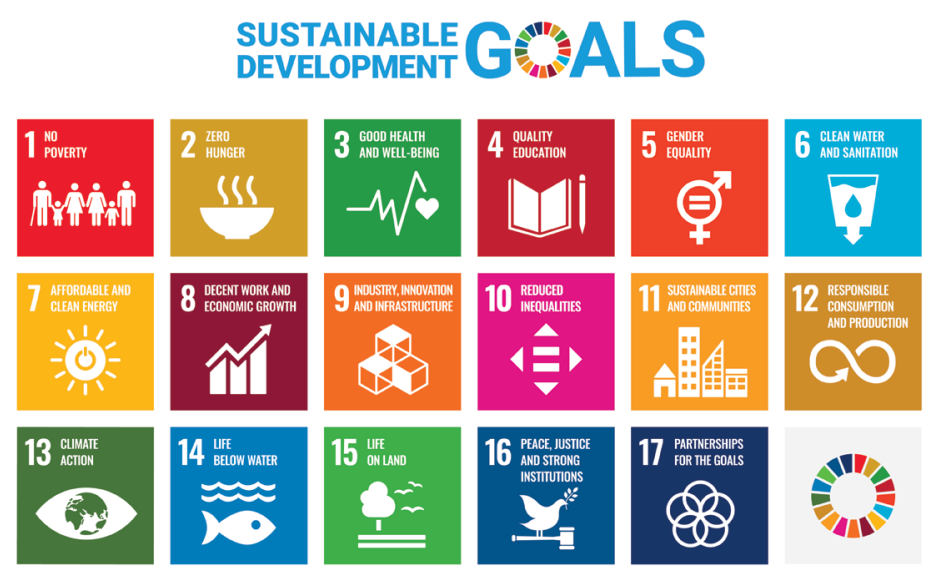

Fig. 1. (Color online) The 17 Sustainable Development Goals proposed by the United Nations. (Source: https:// www.un.org/sustainabledevelopment/blog/2015/12/sustainable-development-goals-kick-off-with-start-of-new-year/) 
different systems: RS, geographic information system (GIS), and global positioning system (GPS). $\mathrm{RS}$ is one of the major applications of sensors in capturing geospatial data, GPS captures locations on Earth, and GIS is the overall system that includes capturing, storing, manipulating, processing, and publishing geospatial data.

\subsection{RS}

In simple terms, RS is sensing something without contact. However, in terms of technology, it is the complete process that captures Earth's surface data using electromagnetic energy and processes and extracts information for the GIS system. Figure 2 shows the elements of RS. On the basis of platforms, RS can be categorized into ground borne, air borne, and space borne, whereas on the basis of the energy source, it can be considered as active or passive. The process from satellite images to information usually takes three steps: preprocessing, image enhancement, and image classification.

\subsection{GIS}

GIS is a complete system that contains information with referenced data to a location. Figure 3 shows the area. It is a system composed of hardware, software database, people, organizations, and procedures. It provides a framework for collecting, storing, retrieving at will, transforming, and displaying spatial data from the real world. It can be used to measure real-world scenarios for mapping, monitoring, and modeling purposes.

\subsection{GPS}

GPS is a network of United States (US) Department of Defense satellites, a group of satellites constantly circling the Earth. It is named as Navigation Satellite Timing and Ranging and originally used to fulfill defense needs, but later declassified to serve the public.

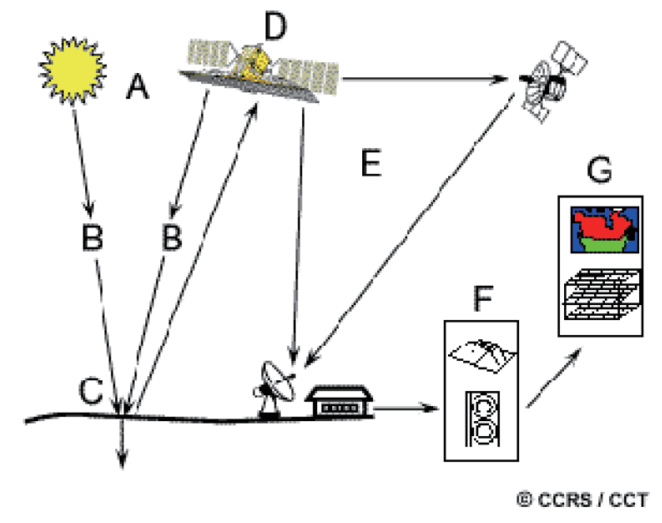
A. Energy Source or Illumination
B. Radiation and the Atmosphere
C. Interaction with the Target
D. Recording of Energy by the Sensor
E. Transmission, Reception, and Processing
F. Interpretation and Analysis
G. Application

Fig. 2. (Color online) Elements of RS. (Source: https://www.nrcan.gc.ca/maps-tools-publications/satelliteimagery-air-photos/remote-sensing-tutorials/fundamentals-remote-sensing-introduction/9363) 


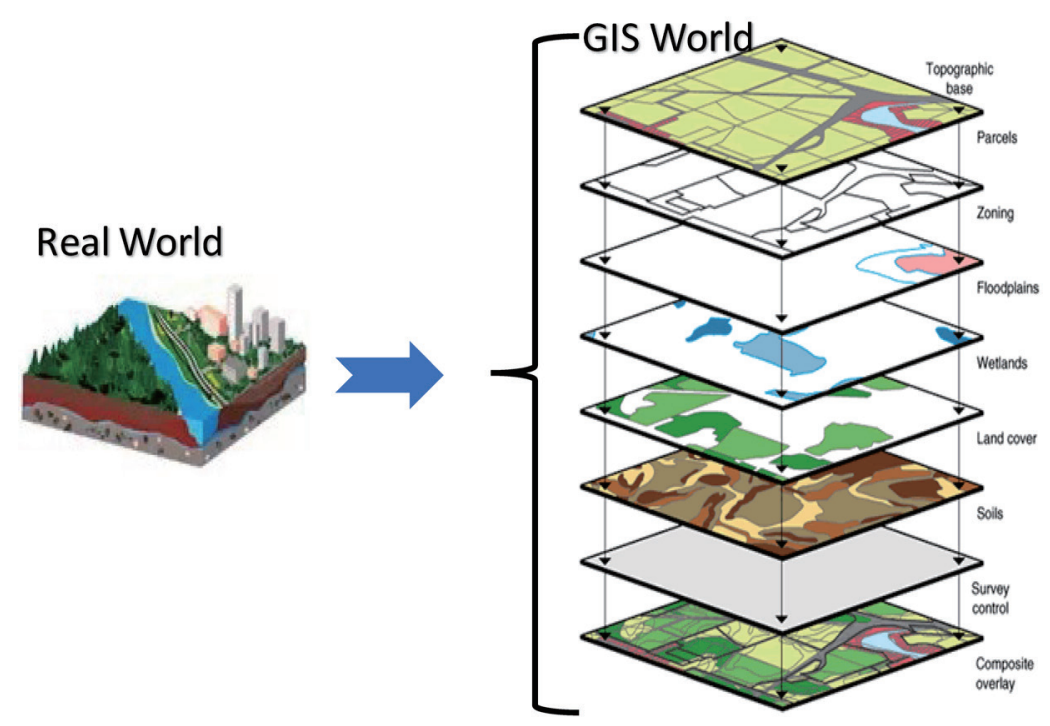

Fig. 3. (Color online) GIS and data layers from the real world. (Source: https://ethiopia-gis.nrel.colostate.edu/gis. php)

However, in general terms, it represents any set of navigation satellites that continuously transmit information in the form of code that makes it possible to identify precise positions on Earth's surface by measuring distances from the satellites. After the launch of different other satellites such as GLObal NAvigation Satellite System, BeiDou Navigation Satellite System, Galileo, Quasi-Zenith Satellite System, and Indian Regional Navigation Satellite System, Global Navigation Satellite System (GNSS) is used as a generic term for satellites that provide autonomous positioning around the globe. GPS is divided into space and ground segments. Furthermore, ground segments can be divided into control and user segments (Fig. 4).

\section{Application of RS and Geospatial Technologies for SDGs}

The fundamental component of sustainable development is accomplishing social and monetary means to improve human personal satisfaction while monitoring and overseeing common assets. ${ }^{(2)}$ Sustainable applications of RS and a geospatial information system for Earth observation (EO) have become more essential in understanding the ecological, environmental, hydrological, geological, and physical characteristics of Earth surfaces for the SDGs. The data and applications will play a major role in strengthening the capacity of national statistical offices and data systems to ensure access to high-quality, timely, reliable, and disaggregated data as SDGs focus on developing countries, particularly African countries, least developed countries, small island developing states, and landlocked developing countries.

RS provides unbiased information, whereas GIS plays an important role in the decision support system for spatial analysis and the database management of natural resources. Although RS and GIS were long prevalent since the beginning of maps, the era of satellite RS began after the successful launch of Sputnik 1, the first artificial satellite of the former Soviet 


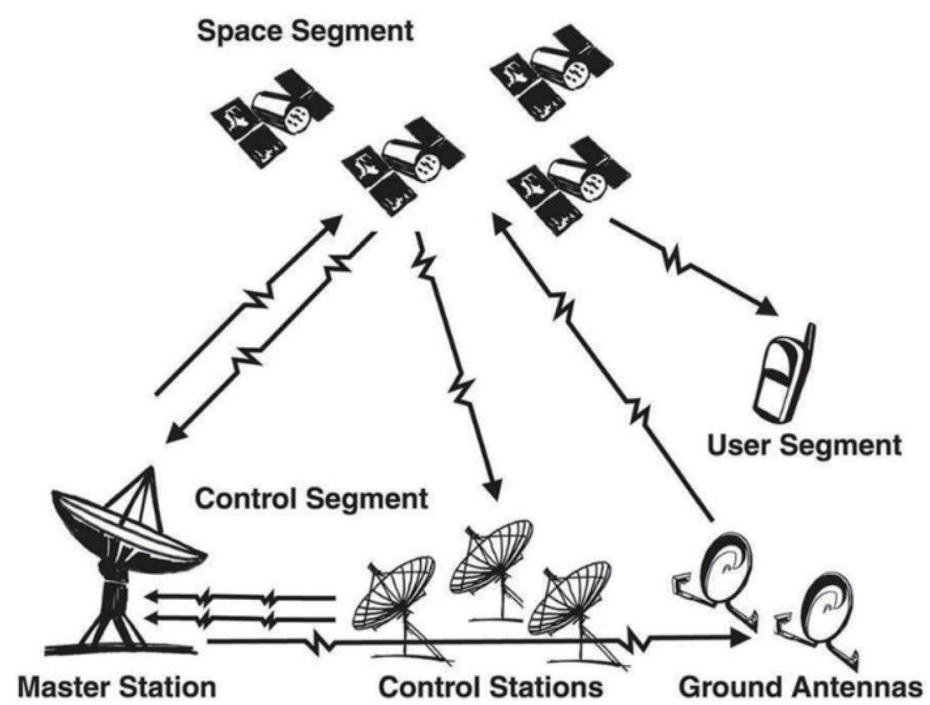

Fig. 4. Segments of GPS. (Source: https://sites.google.com/site/rembeet/summersemester2013/digitalcommunication-systems-elec675/class-work/11-gps-study-referene-material)

Union, on October 4, 1957. ${ }^{(3)}$ Since then, many remote sensors with different capabilities have been providing revolutionary scientific insights on Earth's surface for various purposes. RS provided regional and global perspectives that helped in identifying, understanding, and solving environmental problems on a whole different level. Recent improvements in remote sensors include the launching of satellites with higher frequency and higher resolution images in terms of spectral, radiometric, and spatial extents than earlier satellites.

One of the best examples is the Landsat mission. Landsat satellites have provided satellite imagery of Earth's surface through its sensors since 1972 when the real application for public welfare began. ${ }^{(4)}$ Beginning with the Landsat-MSS data with a $60-80 \mathrm{~m}$ spatial resolution and four spectral bands spanning from green to near-infrared in the early seventies, natural resources scientists had access to Landsat-TM data with a $30 \mathrm{~m}$ spatial resolution and seven spectral bands spread over between blue and thermal infrared regions of the electromagnetic spectrum in the early eighties, which helped further refine and generate thematic information for larger areas. By 2013, the program had launched eight satellites (and is currently working on the ninth expected in 2023) with ever-stronger capacities as can be seen in its basic specifications. Today, Landsat 8 circles 438 miles above Earth and completes 14 orbits per day, recording 115-mile-wide swaths with each 99 min orbit. It uses infrared sensors to yield 400 scenes daily and produces a full Earth scan every 16 days. ${ }^{(5)}$ Owing to the consistent, cross-calibrated set of records, ${ }^{(6)}$ Landsat imagery has maintained a tradition of mapping and monitoring many research studies in agriculture, disaster, forest, and vegetation, hydrology, land use/cover change. ${ }^{(7)}$ Furthermore, high-spatial-resolution satellites, such as Sentinel, SPOT, RapidEye, ALOS, Worldview, GeoEye, KompSat, SkySat, TripleSat, and Pléiades, have supplemented the effort of generating information on natural resources in recent years. The addition of fine spectrums to form hyperspectral sensing has opened opportunities to diagnose and refine finer information 
on natural resources. Similarly, microwave remote sensors open a whole new dimension to explore in EO, which is not affected by weather conditions, and overcome the issue faced during smoke, haze, and cloud cover for optical sensors. The polarimetric images generated from microwave energy with different polarizations provide further insight into the structure and flouristics of vegetation, soil properties, and parent material. Furthermore, radar interferometry is yet another tool that enables DEM generation, which allows monitoring glaciers, volcanic eruption, mine subsidence, mud slips, and so forth. A new generation of satellites such as the Suomi-NPP Visible Infrared Imaging Radiometer Suite (VIIRS), is providing a global measurement of nocturnal visible and near-infrared light that is suitable for Earth science and climate studies. Such data helps in monitoring both the magnitude and signature of nighttime phenomena and the anthropogenic sources of light emissions such as tracking shipping and fishing vessels, and flaring of waste natural gas, in addition to their application to humanitarian efforts, such as the assessment of conflict-associated demographic changes and mapping impoverishment. ${ }^{(8-10)}$

Other forms of data collection are from GNSS measurement. Although started by the USA, many countries now have their own constellation and provide multifrequency data. The growth of the geospatial industry is also due to the readily available GNSS technology that gives a precise location at a higher speed. The technology is used in a small smartwatch as well as big airlines to navigate. For a higher precision, regional augmentation systems such as the Wide Area Augmentation System in North \& South America, the European Geostationary Navigation Overlay Service in Europe, the GPS-aided GEO augmented navigation in India, and the Multifunctional Satellite Augmentation System in Japan are also in use. These systems provide data necessary for the safe navigation of aircraft, drones, and autonomous vehicles. Besides this, GNSS observation is used for monitoring atmosphere and landslides, structure deformation, and precision agriculture. ${ }^{(11-15)}$

The data generated by RS and GPS are integrated with various spatial and nonspatial attributes in the GIS so that they can be useful in an action plan/developmental plan for sustainable development. The variety of applications depends on the kind of information a community needs, depending on goals such as mapping resources, modeling pollution, managing water, traffic or sewers, and predicting disaster to reduce risk and develop resilience. TIGER, which stands for Topographically Integrated Geographic Encoding and Referencing, is a typical example of GIS. ${ }^{(16)}$ It has a data and map format developed by the US Census and Geological Survey incorporating land attributes (roads, buildings, water, and political and administrative boundaries) that can serve as the base for overlaying demographic data for various applications. ${ }^{(16,17)}$ Such a system facilitates spatial analysis to see through the complexity and interrelated nature of the SDGs.

In recent years, geospatial data have become a more relevant and important factor, contributing directly and indirectly to the development of countries. Thus, with these RS and geospatial technologies being adopted, policymakers, such as ministries, can make decisions on land management, mining, forestry, agriculture, water resource management, environment, and urban development. A sample study from Namibia shows that Earth-observation-based results represent a high potential to supplement the national statistics for Namibia or to serve as 
primary data sources once validated through ground-truthing. ${ }^{(18)}$ In the context of the SDGs, the following discussions are some of the applications of RS and geospatial technologies.

Poverty is one of the major hindrances for development and sustainability. Different communities require different approaches to uplift them. Remotely sensed satellite data along with the integration of advanced machine learning methods have been able to map as well as predict poverty on a global scale. ${ }^{(19-21)}$ Indicators such as night lights, ${ }^{(22)}$ deforestation, ${ }^{(23)}$ and environment ${ }^{(24)}$ recorded with satellite imagery help reveal the distribution of poverty and its relationship with other factors such as food and health. ${ }^{(25,26)}$

Food is a major fuel that drives human resources. The second SDG is zero hunger for which enough crops need to be produced worldwide. RS technology helps not only in mapping and estimating crop yields but also in the overall suitability for crops based on geo-climatic parameters. ${ }^{(27-31)}$ Furthermore, the microlevel implementation of geospatial tools is mainly carried out for mapping groundwater resources, drainage patterns, variable rate application, and management of fertilizers, pesticides, and insecticides. ${ }^{(32,33)}$ In general, high-resolution satellites of smaller size seem to contribute more to the local level, whereas mid-resolution ones give regional- or continental-level understanding. ${ }^{(34,35)}$

The geospatial analysis was adopted early in public health to map the cholera outbreak and pinpoint the source. Aside from the geospatial analysis based on various geospatial variables, very high resolution satellite imagery has also been used in the fine-scale mapping of vector habitats and their surveillance for elimination. ${ }^{(36)}$ Investigations on the geographic distribution and modeling of diseases based on their geospatial characteristics have shown links to poverty. ${ }^{(37)}$

Vector-borne diseases are highly interrelated with clean water and sanitation management. As SDG No. 6 focuses on water quality and sanitation, RS techniques have been applied to surface water mapping and monitoring changes, ${ }^{(38-40)}$ and mapping and monitoring changes in water quality parameters ${ }^{(41,42)}$ in regional and long-term cases. ${ }^{(43,44)}$ Special research initiatives such as the Sentinel-1 Program for water management in low-income countries have been used to explore the performance and opportunities provided by the European satellite Sentinel-1 for water resource management applications. ${ }^{(45)}$ Andres et al. reviewed various approaches that can be used to support and achieve water and sanitation targets. ${ }^{(46)}$

Although every developed country is pushing zero emission mandates to mitigate climate change, RS along with geospatial analysis can explore potential for solar and wind energy sites. ${ }^{(47,48)}$ Furthermore, national-scale studies could identify high-priority investment opportunities for clean energy. ${ }^{(49,50)}$ Bosch et al. have presented the global onshore and offshore wind energy potentials with respect to topographical features, land use, and environmental constraints. ${ }^{(51,52)}$

SDG No. 8 is about taking action to eradicate forced labor and end modern slavery and child labor. With the help of RS observations, a modern form of slavery could be traced to industries, countries or regions, and this evidence can be applied in prevention and eradication actions. Some of the examples are mapping industries such as brick kilns, mining, crop harvesting, and fishing or fish processing. ${ }^{(53-55)}$ In some cases, mapping environmental destructions such as pollution, encroachment, and deforestation also relates the environmental relationship with modern slavery. ${ }^{(56)}$ 
Recently, spatial information has become increasingly important as a key factor leading the Fourth Industrial Revolution. The establishment of high-precision spatial information is essential in informed decision-making, impact assessments, and better monitoring, and for achieving productivity and efficiency gains across all professional user domains, namely, architecture, engineering and construction, agriculture, urban planning, defense and intelligence, agriculture, natural resources, disaster management, and so forth. These are promoting the competitiveness of new growth industries, and guidance information is becoming an essential element in promising future industries such as $\mathrm{O} 2 \mathrm{O}$ services that combine online and offline, digital twins, and so forth. According to the GeoBuiz Geospatial Industry Outlook \& Readiness Index 2019, the geospatial industry was valued at an estimated US\$ 339.0 billion in 2018. The cumulative geospatial industry is projected to reach US\$ 439.2 billion by 2020 . This growth is due to the adoption of advanced technologies such as unmanned aerial vehicles (UAVs), Internet of things (IoT), and artificial intelligence (AI) for emerging market segments of smart cities and immersive reality [3D, augmented reality (AR), virtual reality (VR), digital twins] applications, and resultant innovative business models. ${ }^{(57)}$

Collectively with satellite and ground sensors integrated with geospatial technologies, complex components of cities can be monitored for their sustainability. ${ }^{(58,59)}$ High-resolution satellite or aerial imageries can provide a plan view of the cities and can be used to map urban metrics. ${ }^{(60-62)}$ In a more integrated approach, RS imagery has been used in extracting and updating transportation networks, ${ }^{(63-66)}$ buildings,${ }^{(67-70)}$ and impervious areas ${ }^{(71-74)}$ providing land use/cover data and biophysical attributes, ${ }^{(75-77)}$ and detecting urban growth and sprawl. ${ }^{(78-80)}$ Some works have used census data to improve image classification in urban areas ${ }^{(81-83)}$ or integrated with RS to estimate population and residential densities, ${ }^{(84-88)}$ in order to assess socioeconomic conditions, ${ }^{(89,90)}$ and evaluate the quality of life. ${ }^{(91-93)}$ In addition, thermal sensors have also been used in understanding surface urban heat islands, which are a major indicator of sustainability. ${ }^{(94,95)}$ These approaches guide efforts to minimize the damage that urban growth has on the environment and thus help in building smarter and more sustainable cities.

The core idea of the integrated sensor is for measuring different environmental parameters (e.g., water level, air temperature, air moisture, wind speed, and soil moisture), answering user-specific questions and deriving new information rather than merely concatenating sensor information. This information can also be shared with the help of WebGIS. ${ }^{(96-98)}$ Blaschke et al. provided a comprehensive review of integrating geospatial technologies to understand urban systems with the help of various sensors. ${ }^{(99)}$

To maintain sustainability, responsible consumption and production are very important. RS has been long helpful in monitoring the overexploitation of forest, grassland, water, and other natural resources. ${ }^{(100-103)}$ Much of the SDGs cross paths and support each other. For a sustainable environment, climate needs to be also monitored in addition to Earth's surface resources. A good understating of climate science, which provides reliable data on, for example temperature, precipitation, wind, soil moisture, or ocean conditions, as well as assessments, projections, scenarios or vulnerability, and risk analyses, is essential for various sectors. ${ }^{(104)}$ Although both optical and microwave RS systems are used in monitoring climatic factors, 
geospatial technologies such as Google Earth have been used in web-based visualization. ${ }^{(105-107)}$

The water ecosystem plays a major role in balancing Earth's ecosystem. Measuring the sea temperature, monitoring the coastal eutrophication level, and tracking plastic debris in the sea should be constantly carried out. Satellite images have not only been used in mapping sea surface temperature but also assessing the potential for seagrass thermal dynamics. ${ }^{(108,109)}$ Similarly, chlorophyll-a, which directly regulates the eutrophication process, can be monitored using satellite imagery. ${ }^{(110,111)}$ Major plastic pollutants, which form debris, have also been extracted from satellite images, and an observation system based on tracking from satellite imagery has been proposed. ${ }^{(112,113)}$

SDG No. 15 is aimed to protect, restore, and promote the sustainable use of terrestrial ecosystems, sustainably manage forests, combat desertification, halt and reverse land degradation, and halt biodiversity loss. As stated above, RS provides ground truth evidence on what is happening with the land surface. A major indicator in a land surface is forest cover. It changes with respect to the total area change and the proportion of land degraded over the total area of land should also be known for SDGs. These can be carried out through mapping land cover changes using EO data. Having the advantages of large spatial and temporal coverages, the high standardization of data production, and frequent updates at a high reliability and a low cost, open EO solutions are very important for mapping these SDG indicators. ${ }^{(18)}$ On the basis of estimated natural resources loss, restoration action can be taken. ${ }^{(114-116)}$ Although satellites have been improved, their temporal resolution and availability are still a challenge in monitoring fast changes. In recent years, UAVs have been extensively explored for environmental monitoring, management, and evaluation. They have significant impacts on the temporal and spatial resolutions of data at a more cost-effective price than traditional monitoring practices. Thus, they have been widely used for data collection in the monitoring of biomass, forests, and vegetation.

The last two SDGs are promoting peace and partnership to strengthen sustainable goals. Human and environment are interconnected; countries are also interrelated with one another. The Himalayas from Nepal provides fresh water to India and Bangladesh, the Amazon forest extends across various countries in South America and supports them, and cargo vessels in the sea cross different international borders. ${ }^{(117-119)}$ Thus, stakeholders should adopt collaborative measures for the conservation of natural resources and the prevention of natural disasters.

Besides the above-mentioned applications in SDGs, there are several studies that focus on a specific topic of geospatial technology. A booklet published by the Group on EO and the Committee on EO satellites highlights the potential role of EOs particularly in supporting the global indicator framework for SDGs. ${ }^{(120)}$ Anderson et al. reviewed the key role that EOs play in achieving the SDGs as articulated in the 2030 Agenda document and in monitoring, measuring, and reporting progress towards the associated targets. ${ }^{(121)}$ Maso et al. have provided a study with a more detailed link between RS data and essential variables for SDGs. ${ }^{(122)}$ Similarly, Holloway and Mengersen ${ }^{(2)}$ reviewed statistical machine learning methods and RS for SDGs. Furthermore, applications and reviews on the technology for SDGs can be found in various publications. 


\section{Opportunities and Challenges}

In the future, the growth of emerging technologies such as AI, Digital Twins, VR, IoT as well as participatory sensing and humans-as-sensors (crowdsourcing, VGI, and citizen science) will change the way we think, live, and work. Geospatial data and technology will be integrated with emerging technologies to advance new tools for sustainable development and regional decision support systems. These big-data-driven algorithms and apps will be more contextual than ever, combining users' habits and preferences with situations and locations, to provide smart notification services and location-aware virtual assistants that seamlessly follow users as they roam between different environments and devices. Geospatial and RS data will help in providing real-time integration, quality checking, and location-enabled data analysis.

A huge amount of data arises from an almost continuous stream of diverse sources such as in situ sensor measurements, EO data, and projection data. Integrated new technology can be used in various fields for facilitating tasks and decision-making. One example is the use of AR and geospatial technology in historical places to augment the knowledge of tourists and to make an impression on users with the new technologies. The advantages of adopting the technologies are multilanguage support, easy understanding, mobility, and maintenance.

Nonetheless, with advancing technology, there are still challenges and limitations in using geospatial technologies in future works. Challenges are related to the RS data itself that is continuously produced by many RS satellites as well as various ground sensors. The data must deal with sensor calibration, data quality, privacy and uncertainties, download, interoperability, processing, and visualization. In the case of processing RS data, although many studies have improved accuracy, classifications remain a major challenge, owing to the (a) complexity of the environment, (b) limitations of image processing techniques, and (c) complexities and nuances in integrating or fusing multisource data. ${ }^{(123)}$ Spectral uncertainties such as water with shadow, bare soil and/or dry mud with impervious surfaces are also issues in land cover/use mapping. Furthermore, the concentration of diverse built-up materials in a small area results in pixel generalization, eventually leading to classification errors, which can be particularly problematic when working with low-resolution images. Many of these efforts have relied upon custodial GIS, and most of these base maps were limited to two-dimensional representations, with 3D functionalities being limited to a narrow set of applications. ${ }^{(99)}$ Multidisciplinary approaches in RS can be introduced for a better and deeper understanding of human-environment interactions. The increase in the amount of data will require an increase in the data processing power of hardware for processing high data volume and increasing the capacity of servers. New technology requires highly skilled manpower in IT and geospatial sectors. Another major challenge will be to produce enough new manpower as well as train those who are using the traditional method to cope with new technologies. ${ }^{(124)}$ Furthermore, these technologies are constantly changing and improving, making it even more difficult for practitioners to track updates about potential uses and applications.

Although developed countries have resources and data, many developing countries face major challenges owing to the availability of timely and accurate location data, the lack of skilled manpower, and limited awareness about these technologies among environmental 
decision/policy makers and their prospective users. Despite the tremendous potential geospatial technologies offer, there are still fears among traditional practitioners in developing countries. Thus, the lack of budget to fund the adoption of these technologies is another major challenge. These countries and regions are those that are most affected by global environmental changes and must be encouraged to achieve global sustainability.

\section{Acknowledgments}

The authors would like to thank MYU Research, Japan for polishing and supporting the publication fee of the paper.

\section{References}

1 A. Farshad and J. A. Zinck: Agric. Ecosyst. Environ. 47 (1993) 1. https://doi.org/10.1016/0167-8809(93)90132-

2 J. Holloway and K. Mengersen: Remote Sens. 10 (2018) 1365. https://doi.org/10.3390/rs10091365

3 A. J. Tatem, S. J. Goetz, and S. I. Hay: Am. Sci. 96 (2008) 390. https://doi.org/10.1511/2008.74.390

4 U. S. Geological Survey: FS 2012-3072 (2012) 1. https://pubs.usgs.gov/fs/2012/3072/fs2012-3072.pdf

5 T. D. Acharya and I. T. Yang: IJIEASR 4 (2015) 4.

6 G. Chander, B. L. Markham, and D. L. Helder: Remote Sens. Environ. 113 (2009) 893. https://doi.org/10.1016/ j.rse.2009.01.007

7 A. S. Belward and J. O. Skøien: ISPRS J. Photogramm. Remote Sens. 103 (2015) 115. https://doi.org/10.1016/ j.isprsjprs.2014.03.009

8 K. Shi, B. Yu, Y. Huang, Y. Hu, B. Yin, Z. Chen, L. Chen, and J. Wu: Remote Sens. 6 (2014) 1705. https://doi. org $/ 10.3390 /$ rs 6021705

9 B. Yu, K. Shi, Y. Hu, C. Huang, Z. Chen, and J. Wu: IEEE J. Sel. Top. Appl. Earth Obs. Remote Sens. 8 (2015) 1217.

10 K. Shi, B. Yu, Y. Hu, C. Huang, Y. Chen, Y. Huang, Z. Chen, and J. Wu: GIScience Remote Sens. 52 (2015) 274. https://doi.org/10.1080/15481603.2015.1022420

11 S. Jin, G.P. Feng, and S. Gleason: Adv. Space Res. 47 (2011) 1645. https://doi.org/10.1016/j.asr.2011.01.036

12 M. Bender, R. Stosius, F. Zus, G. Dick, J. Wickert, and A. Raabe: Adv. Space Res. 47 (2011) 886. https://doi. org/10.1016/j.asr.2010.09.011

13 T. Bellone, P. Dabove, A. M. Manzino, and C. Taglioretti: Geomatics Nat. Hazards Risk 7 (2016) 458. https:// doi.org/10.1080/19475705.2014.966867

14 J. Xin, J. Zhou, S. Yang, X. Li, and Y. Wang: Sensors 18 (2018) 298. https://doi.org/10.3390/s18010298

15 J. Guo, X. Li, Z. Li, L. Hu, G. Yang, C. Zhao, D. Fairbairn, D. Watson, and M. Ge: Precis. Agric. 19 (2018) 895. https://doi.org/10.1007/s11119-018-9563-8

16 R. W. Marx: Government Publ. Rev. 13 (1986) 181. https://doi.org/10.1016/0277-9390(86)90003-8

17 R. E. Klosterman and A. A. Lew: J. Am. Plann. Assoc. 58 (1992) 379. https://doi. org/10.1080/01944369208975817

18 V. Mariathasan, E. Bezuidenhoudt, and K. R. Olympio: Remote Sens. 11 (2019) 1612. https://doi.org/10.3390/ rs11131612

19 C. D. Elvidge, P.C. Sutton, T. Ghosh, B. T. Tuttle, K. E. Baugh, B. Bhaduri, and E. Bright: Comput. Geosci. 35 (2009) 1652. https://doi.org/10.1016/j.cageo.2009.01.009

20 N. Jean, M. Burke, M. Xie, W. M. Davis, D. B. Lobell, and S. Ermon: Science 353 (2016) 790. https://doi. org/10.1126/science.aaf7894

21 J. E. Steele, P. R. Sundsøy, C. Pezzulo, V. A. Alegana, T. J. Bird, J. Blumenstock, J. Bjelland, K. Engø-Monsen, Y. de Montjoye, and A. M. Iqbal: J. R. Soc. Interface 14 (2017) 20160690. https://doi.org/10.1098/rsif.2016.0690

22 W. Wang, H. Cheng, and L. Zhang: Adv. Space Res. 49 (2012) 1253. https://doi.org/10.1016/j.asr.2012.01.025

23 D. L. A. Gaveau, M. Linkie, Suyadi, P. Levang, and N. Leader-Williams: Biol. Conserv. 142 (2009) 597. https://doi.org/10.1016/j.biocon.2008.11.024

24 G. R. Watmough, P. M. Atkinson, A. Saikia, and C. W. Hutton: World Dev. 78 (2016) 188. https://doi. org/10.1016/j.worlddev.2015.10.031 
25 G. Hyman, C. Larrea, and A. Farrow: Food Policy 30 (2005) 453. https://doi.org/10.1016/j.foodpol.2005.10.003

26 L. Sedda, A. J. Tatem, D. W. Morley, P. M. Atkinson, N. A. Wardrop, C. Pezzulo, A. Sorichetta, J. Kuleszo, and D. J. Rogers: Int. Health 7 (2015) 99. https://doi.org/10.1093/inthealth/ihv005

27 S. S. Panda, G. Hoogenboom, and J. O. Paz: Remote Sens. 2 (2010) 1973. https://doi.org/10.3390/rs2081973

28 A. Shelestov, M. Lavreniuk, N. Kussul, A. Novikov, and S. Skakun: Front. Earth Sci. 5 (2017) 17. https://doi. org/10.3389/feart.2017.00017

29 F. Dell'Acqua, G. Iannelli, M. Torres, and M. Martina: Sensors 18 (2018) 591. https://doi.org/10.3390/ s18020591

30 P. K. Kingra, R. Setia, S. Kaur, S. Singh, S. P. Singh, S. S. Kukal, and B. Pateriya: Spatial Inf. Res. 26 (2018) 381. https://doi.org/10.1007/s41324-018-0182-2

31 F. Kogan, W. Guo, and W. Yang: Geomatics, Nat. Hazards and Risk 10 (2019) 651. https://doi.org/10.1080/194 75705.2018 .1541257

32 Geospatial Media and Communications Pvt. Ltd.: Geospatial Technology in Agriculture Industry Trends \& Prospects 2015 Report (2015). https://geospatialmedia.net/agriculture-industry-report.html

33 R. T. Das and S. Pal: Spatial Inf. Res. 25 (2017) 467. https://doi.org/10.1007/s41324-017-0114-6

34 Y. O. Ouma: Adv. Space Res. 57 (2016) 110. https://doi.org/10.1016/j.asr.2015.10.038

35 S. Madry, P. Martinez, and R. Laufer: Innovative Design, Manufacturing and Testing of Small Satellites (Springer Praxis Books, Chichester, 2018) p. 65. https://doi.org/10.1007/978-3-319-75094-1_5

36 J. B. Malone, R. Bergquist, M. Martins, and J. C. Luvall: Tropical Med. Infect. Dis. 4 (2019) 15. https://doi. org/10.3390/tropicalmed4010015

37 J. B. Malone and N. R. Bergquist: Geospatial Health 6 (2012) S1. https://doi.org/10.4081/gh.2012.115

38 T. D. Acharya, A. Subedi, and D. H. Lee: Sensors 8 (2018) 2580. https://doi.org/10.3390/s18082580

39 T. D. Acharya, A. Subedi, and D. H. Lee: Sensors 19 (2019) 2769. https://doi.org/10.3390/s19122769

40 T. D. Acharya, A. Subedi, H. Huang, and D. H. Lee: Sens. Mater. 31 (2019) 1429. https://doi.org/10.18494/ sam.2019.2264

41 T. Dube, O. Mutanga, K. Seutloali, S. Adelabu, and C. Shoko: Afr. J. Aquat. Sci. 40 (2015) 1. https://doi.org/10. 2989/16085914.2015.1014994

42 M. H. Gholizadeh, A. M. Melesse, and L. Reddi: Sensors 16 (2016) 1298. https://doi.org/10.3390/s16081298

43 L. G. Olmanson, P. L. Brezonik, and M. E. Bauer: Water Resour. Res. 47 (2011). https://doi. org/10.1029/2011wr011005

44 C. E. Binding, T. A. Greenberg, S. B. Watson, S. Rastin, and J. Gould: Limnol. Oceanogr. 60 (2015) 1976. https://doi.org/10.1002/lno.10146

45 D. Amitrano, G. Martino, A. Iodice, F. Mitidieri, M. Papa, D. Riccio, and G. Ruello: Remote Sens. 6 (2014) 10676. https://doi.org/10.3390/rs61110676

46 L. Andres, K. Boateng, C. Borja-Vega, and E. Thomas: Water 10 (2018) 756. https://doi.org/10.3390/w10060756

47 S. Lee, B. Bush and R. George: Sol. Energy 85 (2011) 1945. https://doi.org/10.1016/j.solener.2011.05.005

48 M. A. Anwarzai and K. Nagasaka: Renewable Sustainable Energy Rev. 71 (2017) 150. https://doi.org/10.1016/ j.rser.2016.12.048

49 S. Samanta, D. K. Pal, S.S. Aiau, and B. Palsamanta: Spatial Inf. Res. 24 (2016) 531. https://doi.org/10.1007/ s41324-016-0050-x

50 K. Shiraishi, R. G. Shirley, and D. M. Kammen: Appl. Energy 235 (2019) 1457. https://doi.org/10.1016/ j.apenergy.2018.10.123

51 J. Bosch, I. Staffell, and A. D. Hawkes: Energy 131 (2017) 207. https://doi.org/10.1016/j.energy.2017.05.052

52 J. Bosch, I. Staffell, and A. D. Hawkes: Energy 163 (2018) 766. https://doi.org/10.1016/j.energy.2018.08.153

53 B. L. Card and I. L. Baker: Genocide Stud. Prev.: Int. J. 8 (2014) 7. https://doi.org/10.5038/1911-9933.8.3.5

54 D. S. Boyd, B. Jackson, J. Wardlaw, G. M. Foody, S. Marsh, and K. Bales: ISPRS J. Photogramm. Remote Sens. 142 (2018) 380. https://doi.org/10.1016/j.isprsjprs.2018.02.012

55 G. M. Foody, F. Ling, D. S. Boyd, X. Li, and J. Wardlaw: Remote Sens. 11 (2019) 266. https://doi.org/10.3390/ rs11030266

56 B. Jackson, K. Bales, S. Owen, J. Wardlaw, and D. S. Boyd: J. Mod. Slavery 4 (2018) 169.

57 GeoBuiz: Geospatial Industry Outlook \& Readiness Index 2019 (2019) https:/geobuiz.com/geobuizreport-2019/

58 E. Andersson: Ecol. Soc. 11 (2006) 34. https://doi.org/10.5751/ES-01639-110134

59 P. J. Hardin, M. W. Jackson, and S. M. Otterstrom: Mapping, Measuring, and Modeling Urban Growth (Springer, Heidelberg, 2007) p. 141. https://doi.org/10.1007/978-3-540-69417-5_8

60 T. Rashed and C. Jürgens: Remote Sensing of Urban and Suburban Areas (Springer, Heidelberg, 2010). p. 120 https://doi.org/10.1007/978-1-4020-4385-7 
61 Q. Weng and D. A. Quattrochi: Urban Remote Sensing (CRC Press, Boca Raton, 2018). https://doi. org/10.1201/9781315166612

62 M. Ehlers: Urban Remote Sensing: New Developments and Trends, Eds. Q. Weng and D. A. Quattrochi (CRC Press, Boca Raton, 2018) Chap. 17.

63 A. K. Shackelford and C. H. Davis: IGARSS 2003. 2003 IEEE Int. Geoscience and Remote Sens. Symp. Proceedings (IEEE Cat. No. 03CH37477) 1 (2003) 461. https://doi.org/10.1109/IGARSS.2003.1293809

64 J. B. Mena and J. A. Malpica: Pattern Recognit. Lett. 26 (2005) 1201. https://doi.org/10.1016/j.patrec.2004.11.005

65 H. Tømmervik, B. Johansen, K. A. Høgda, and K. B. Strann: Land Degrad. Dev. 23 (2012) 43. https://doi. org/10.1002/ldr.1047

66 A. D. Nagne and B. W. Gawali: IJERA 3 (2013) 70. https://pdfs.semanticscholar.org/5f5c/ f446620dccef5839f1b02a6b43373c7863a2.pdf

67 A. K. Shackelford, C. H. Davis, and X. Wang: IGARSS 2004. 2004 IEEE Int. Geoscience and Remote Sens. Symp. 3 (2004) 1996. https://doi.org/10.1109/IGARSS.2004.1370739

68 X. Jin and C. H. Davis: EURASIP J. Adv. Signal Process. 2005 (2005) 745309. https://doi.org/10.1155/ ASP.2005.2196

69 G. Sohn and I. Dowman: ISPRS J. Photogramm. Remote Sens. 62 (2007) 43. https://doi.org/10.1016/ j.isprsjprs.2007.01.001

70 A. O. Ok, C. Senaras, and B. Yuksel: IEEE Trans. Geosci. Remote Sens. 51 (2013) 1701. https://doi.org/10.1109/ TGRS.2012.2207123

71 D. Lu, G. Li, W. Kuang, and E. Moran: Int. J. Digital Earth 7 (2014) 93. https://doi.org/10.1080/17538947.2013. 866173

72 J. Yang and P. Li: Remote Sens. Appl.: Soc. Environ. 1 (2015) 61. https://doi.org/10.1016/j.rsase.2015.06.005

73 A. R. Shahtahmassebi, J. Song, Q. Zheng, G. A. Blackburn, K. Wang, L. Y. Huang, Y. Pan, N. Moore, G. Shahtahmassebi, R. Sadrabadi Haghighi, and J. S. Deng: Int. J. Appl. Earth Obs. Geoinf. 46 (2016) 94. https:// doi.org/10.1016/j.jag.2015.11.007

74 A. Sekertekin, S. Abdikan, and A. M. Marangoz: Environ. Monit. Assess. 190 (2018) 381. https://doi. org/10.1007/s10661-018-6767-3

75 J. Huang, X. X. Lu, and J. M. Sellers: Landscape Urban Plann. 82 (2007) 184. https://doi.org/10.1016/ j.landurbplan.2007.02.010

76 B. Lalljee and S. Facknath: Land Use: Reflection on Spatial Informatics Agriculture and Development (Concept Publishing, New Delhi, 2008) p. 231.

77 T. D. Acharya, I. T. Yang, and D. H. Lee: Appl. Sci. 6 (2016) 371. https://doi.org/10.3390/app6110371

78 U. Heiden, W. Heldens, S. Roessner, K. Segl, T. Esch, and A. Mueller: Landscape Urban Plann. 105 (2012) 361. https://doi.org/10.1016/j.landurbplan.2012.01.001

79 K. Cockx, T. Van de Voorde, and F. Canters: Int. J. Appl. Earth Obs. Geoinf. 31 (2014) 154. https://doi. org/10.1016/j.jag.2014.03.016

80 T. D. Acharya, J. Parajuli, K. Shahi, D. Poudel, and I.T. Yang: Int. J. of IT, Eng. \& Appl. Sci. Res. (IJIEASR) 4 (2014) 1.

81 V. Mesev: Photogramm. Eng. Remote Sens. 64 (1998) 431.

82 Q. Weng: Remote sensing and GIS Integration: Theories, Methods, and Applications (McGraw-Hill, New York, 2010)

83 T. D. Acharya, I. T. Yang, and D. H. Lee: Sens. Mater 30 (2018) 1753. https://doi.org/10.18494/SAM.2018.1866

84 M. Langford, D. Maguire, and D. Unwin: The Areal Interpolation Problem: Estimating Population Using Remote Sensing in a GIS Framework, Eds. I. Masser and M. Blakemore (Longman, London, 1991) p. 55.

85 P. Sutton: Comput. Environ. Urban Syst. 21 (1997) 227. https://doi.org/10.1016/S0198-9715(97)01005-3

86 D. Martin, N. J. Tate, and M. Langford: Trans. GIS 4 (2000) 343. https://doi.org/10.1111/1467-9671.00060

87 F. Qiu, K. L. Woller, and R. Briggs: Photogramm. Eng. Remote Sens. 69 (2003) 1031. https://doi.org/10.14358/ PERS.69.9.1031

88 G. Li and Q. Weng: Can. J. Remote Sens. 36 (2010) 155. https://doi.org/10.5589/m10-035

89 C. N. Thomson and P. Hardin: Cities 17 (2000) 97. https://doi.org/10.1016/S0264-2751(00)00005-6

90 G. B. Hall, N. W. Malcolm, and J. M. Piwowar: Trans. GIS 5 (2001) 235. https://doi.org/10.1111/14679671.00080

91 C. P. Lo and B. J. Faber: Remote Sens. Environ. 62 (1997) 143. https://doi.org/10.1016/S0034-4257(97)00088-6

92 C. Weber and J. Hirsch: Int. J. Remote Sens. 13 (1992) 3251. https://doi.org/10.1080/01431169208904116

93 B. Liang and Q. Weng: IEEE J. Sel. Top. Appl. Earth Obs. Remote Sens. 4 (2011) 43. https://doi.org/10.1109/ JSTARS.2010.2060316

94 M. S. Jin, W. Kessomkiat, and G. Pereira: Remote Sens. 3 (2011) 83.https://doi.org/10.3390/rs3010083

95 S. Bonafoni, G. Baldinelli, and P. Verducci: Sustainable Cities Soc. 29 (2017) 211. https://oi.org/10.1016/ j.scs.2016.11.005 
96 M. Kulawiak, A. Prospathopoulos, L. Perivoliotis, M. łuba, S. Kioroglou, and A. Stepnowski: Comput. Geosci. 36 (2010) 1069. https://doi.org/10.1016/j.cageo.2010.02.008

97 P. McCord, F. Tonini, and J. Liu: Appl. Geogr. 96 (2018) 16. https://doi.org/10.1016/j.apgeog.2018.05.001

98 V. V. Hnatushenko, K. Y. Sierikova, and I. Y. Sierikov: 2018 IEEE 13th Int. Scientific and Technical Conf. Computer Sciences and Information Technologies (CSIT) 1 (2018) 270. https://doi.org/10.1109/STCCSIT.2018.8526717

99 T. Blaschke, G. J. Hay, Q. Weng, and B. Resch: Remote Sens. 3 (2011) 1743. https://doi.org/10.3390/rs3081743

100 M. Reiche, R. Funk, Z. Zhang, C. Hoffmann, J. Reiche, M. Wehrhan, Y. Li, and M. Sommer: Grassland Sci. 58 (2012) 8. https://doi.org/10.1111/j.1744-697X.2011.00235.x

101 S. Al-Zyoud, W. Rühaak, E. Forootan, and I. Sass: Resources 4 (2015) 819. https://doi.org/10.3390/ resources4040819

102 J. Reiche, R. Lucas, A. L. Mitchell, J. Verbesselt, D. H. Hoekman, J. Haarpaintner, J. M. Kellndorfer, A. Rosenqvist, E. A. Lehmann, and C. E. Woodcock: Nat. Clim. Change 6 (2016) 120. https://doi.org/10.1038/ nclimate2919

103 J. C. Cuaresma, O. Danylo, S. Fritz, I. McCallum, M. Obersteiner, L. See, and B. Walsh: Sci. Rep. 7 (2017) 40678. https://doi.org/10.1038/srep40678

104 G. Giuliani, S. Nativi, A. Obregon, M. Beniston, and A. Lehmann: Clim. Serv. 8 (2017) 44. https://doi. org/10.1016/j.cliser.2017.08.003

105 X. Sun, S. Shen, G.G. Leptoukh, P. Wang, L. Di, and M. Lu: Comput. Geosci. 47 (2012) 160. https://doi. org/10.1016/j.cageo.2011.09.010

106 C. Stubenrauch, W. Rossow, S. Kinne, S. Ackerman, G. Cesana, H. Chepfer, L. Di Girolamo, B. Getzewich, A. Guignard, and A. Heidinger: Bull. Am. Meteorol. Soc. 94 (2013) 1031. https://doi.org/10.1175/ BAMS-D-12-00117.1

107 F. J. Wentz: J. Clim. 28 (2015) 6882. https://doi.org/10.1175/JCLI-D-15-0155.1

108 P. C. Goela, C. Cordeiro, S. Danchenko, J. Icely, S. Cristina, and A. Newton: J. Mar. Syst. 163 (2016) 12. https://doi.org/10.1016/j.jmarsys.2016.06.002

109 S. R. Phinn, E. M. Kovacs, C. M. Roelfsema, R. F. Canto, C. J. Collier, and L. J. McKenzie: Int. J. Digital Earth 11 (2018) 803. https://doi.org/10.1080/17538947.2017.1359343

110 L. Han and K. J. Jordan: Int. J. Remote Sens. 26 (2005) 5245. https://doi.org/10.1080/01431160500219182

111 N. Wagle, T. D. Acharya, and D. H. Lee: Proc. 6th Int. Electronic Conference on Sensors and Applications (ECSA-6, 2019) 1-6. https://doi.org/10.3390/ecsa-6-06545

112 T. Aoyama: 10778 (2018) 107780R.

113 N. Maximenko, P. Corradi, K. L. Law, E. Van Sebille, S. P. Garaba, R. S. Lampitt, F. Galgani, V. MartinezVicente, L. Goddijn-Murphy, and J. M. Veiga: Front. Mar. Sci. 6 (2019) 447. https://doi.org/10.3389/ fmars.2019.00447

114 P. G. Molin, S. E. Gergel, B. S. Soares-Filho, and S. F. B. Ferraz: Landscape Ecol. 32 (2017) 857. https://doi. org/10.1007/s10980-017-0490-2

115 S. Turubanova, P. V. Potapov, A. Tyukavina, and M. C. Hansen: Environ. Res. Lett. 13 (2018) 074028. https:// doi.org/10.1088/1748-9326/aacd1c

116 Y. Qin, X. Xiao, J. Dong, Y. Zhang, X. Wu, Y. Shimabukuro, E. Arai, C. Biradar, J. Wang, and Z. Zou: Nat. Sustainability 2 (2019) 764. https://doi.org/10.1038/s41893-019-0336-9

117 H. Eva, S. Carboni, F. Achard, N. Stach, L. Durieux, J. Faure, and D. Mollicone: ISPRS J. Photogramm. Remote Sens. 65 (2010) 191. https://doi.org/10.1016/j.isprsjprs.2009.10.008

118 E. Salameh, F. Frappart, F. Papa, A. Güntner, V. Venugopal, A. Getirana, C. Prigent, F. Aires, D. Labat, and B. Laignel: Water 9 (2017) 245. https://doi.org/10.3390/w9040245

119 D. C. Dunn, C. Jablonicky, G. O. Crespo, D. J. McCauley, D. A. Kroodsma, K. Boerder, K. M. Gjerde, and P. N. Halpin: Fish Fish. 19 (2018) 729. https://doi.org/10.1111/faf.12285

120 JAXA: Earth Observations in Support of the 2030 Agenda for Sustainable Development (2017) https://www. earthobservations.org/documents/publications/201703_geo_eo_for_2030_agenda.pdf

121 K. Anderson, B. Ryan, W. Sonntag, A. Kavvada, and L. Friedl: Geo-spatial Inf. Sci. 20 (2017) 77. https://doi.or $\mathrm{g} / 10.1080 / 10095020.2017 .1333230$

122 J. Masó, I. Serral, C. Domingo-Marimon, and A. Zabala: Int. J. Digital Earth (2019) 1. https://doi.org/10.1080/1 7538947.2019.1576787

123 N. Kadhim, M, Mourshed, and M. Bray: Euro- Mediterr. J. Environ. Integr. 1 (2016) 7. https://doi.org/10.1007/ s41207-016-0007-4

124 World Geospatial Industry Council: Geospatial Outlook for User Industries (2019) p. 12. https://wgicouncil. org/wp-content/uploads/2019/05/Industry-Report.pdf 


\section{About the Authors}

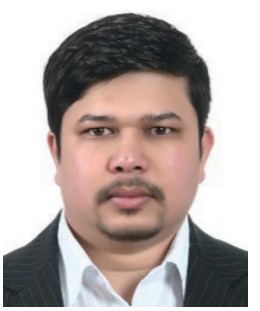

Tri Dev Acharya received his B.E. degree in Geomatics from Kathmandu University, Nepal, in 2011 and his Combined M.S., and Ph.D. degrees from Kangwon National University, Korea, in 2018. He is now a postdoctoral researcher in the same university. His research interests are in data preparation, modeling, and simulation of land cover, surface water, and natural hazards using various machine learning algorithms and geospatial technologies. (tridevacharya@kangwon.ac.kr)

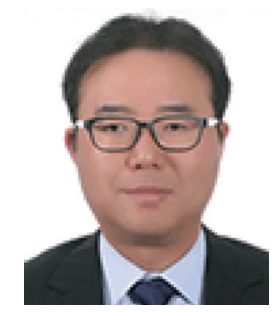

Dong Ha Lee received his B.E., M.S., and Ph.D. degrees from Sungkyunkwan University, Korea, in 2000, 2003, and 2008, respectively. Since 2015, he has been an assistant professor at Kangwon National University, Korea. His research interests are in geodesy, surveying, geospatial information, and natural hazard analysis. (geodesy@kangwon.ac.kr) 